\title{
Intervenção em práticas de cuidado à criança no contexto hospitalar: representações sociais da equipe de saúde ${ }^{1}$
}

\author{
Intervention in child care practices in the hospital context: social representations of \\ the health team
}

\author{
Érica Nayla Harrich Teibel ${ }^{2}$ \\ Daniela Barros da Silva Freire Andrade ${ }^{3}$
}

\begin{abstract}
RESUMO: Esse estudo tem como objetivo compreender e identificar redes de significações sobre práticas do cuidado à criança no contexto hospitalar, segundo profissionais que trabalham em uma Enfermaria Pediátrica. Para tanto se fundamenta na Teoria das representações sociais, elencando pontos possíveis de articulação com os estudos de Bruner sobre a narrativa, buscando a compreensão sobre as imbricações em relação a um projeto de intervenção e o compartilhamento de significados. Foram realizadas onze entrevistas semiestruturadas com profissionais de diferentes áreas de atuação que trabalham em uma enfermaria pediátrica de um hospital universitário. O corpus foi processado pelo programa computacional IRAMUTEQ que permitiu a realização da análise de Classificação Hierárquica Descendente favorecendo a identificação de diferentes classes nas narrativas apresentadas. Para efeito deste trabalho, foi analisada a classe 1 intitulada $A$ prática de sentar e contar história que indicou a presença de diferentes significações sobre o cuidado de crianças no contexto hospitalar junto aos profissionais entrevistados. Elas remetem historicamente tanto ao paradigma da Medicina flexneriana quanto ao da Política Nacional de Humanização, e se apresentaram como matéria prima para a elaboração de novas narrativas, retratando diferentes contextos de interação nas práticas de cuidado abordadas.
\end{abstract}

Palavras-chave: práticas de cuidado; narrativa; representações sociais; enfermaria pediátrica.

ABSTRACT: This study aims to comprehend and identify the meanings' network about the child care practices in the hospital context according to the professional staff that work in a pediatric ward. Therefore, its fundamentals is based on the social representations theory (Moscovici, 2012), connecting the possible articulation points with the studies of Bruner about the narrative (2001, 2002, 2008, 2014), searching for an understanding about the imbrication of an intervention project and meanings sharing (Jodelet, 2007). Eleven semi structured interviews were realized with the professional staff of different fields of action that work in a pediatric ward in a university hospital. The study corpus was processed by the computational program IRAMUTEQ that allowed the realization of the Descendent Hierarchical Classification analyses favoring the identification of different classes in the represented narratives. For the purpose of this work, the Class One entitled as The practice of sitting and storytelling was analyzed and indicated the presence of a few different meanings about the child care in the hospital context among the interviewed professionals. The meanings refer historically to both the Flexnerian Medicine Paradigm and to the Humanization National Politics, and presented themselves as raw material to the new narratives elaboration, delineating different contexts of interaction on the approached practices and cares.

Keywords: care practices; narrative; social representations; pediatric ward.

\footnotetext{
${ }^{1}$ Apoio: CAPES

2 Doutora em Educação pelo Programa de Pós-Graduação em Educação da Universidade Federal de Mato Grosso. Pesquisadora do Grupo de Pesquisa em Psicologia da Infância (GPPIN) - Cuiabá, MT, Brasil. E-mail: ericanayla@yahoo.com.br.

3 Professora do Programa de Pós-Graduação em Educação da Universidade Federal de Mato Grosso. Coordenadora do Grupo de Pesquisa em Psicologia da Infância (GPPIN) - Cuiabá, MT, Brasil.
} 


\section{Introdução e objetivo}

Em seu ensaio sobre Educação, Arendt (1990) destaca a importância de que as crianças sejam apresentadas pelos adultos ao mundo comum para que possam futuramente assumir responsabilidades sobre ele. Suas reflexões permitem considerar que a criança ao ser inserida no hospital encontra uma série de tradições de cuidados já estabelecidas e que precisam ser mediadas pelos adultos para que ela possa compreendê-las, tornando sua estadia nesse lugar significativa e possibilitando que em algum momento ela consiga vivenciar o autocuidado sendo protagonista em seu tratamento.

Sob outra perspectiva, Vigotski (2010) propõe o conceito de zona de desenvolvimento iminente para reforçar que as relações estabelecidas entre a criança e o seu entorno social apresentam-se como fonte de desenvolvimento. Segundo o autor, a impossibilidade de interações com os conhecimentos sistematizados pela sociedade - forma final - pode dificultar a inserção da criança na realidade social e, por conseguinte, prejudicar desenvolvimento. A partir disso, é possível considerar que as interações, aqui compreendidas na perspectiva de um projeto de intervenção, promovidas pelos profissionais no cenário hospitalar durante a prática de cuidados podem fornecer à criança possibilidades de acessar conhecimentos que favoreçam o desenvolvimento do autocuidado em saúde, contribuindo para o processo de significação de si e para a tomada de consciência sobre a sua inserção no contexto hospitalar e para além dele.

Essa abordagem pressupõe que significados construídos historicamente e instituídos socialmente podem influenciar o processo de significação da criança por meio da sua interação com os sujeitos e artefatos culturais presentes no espaço hospitalar. Com isso, entende-se que as representações sociais dos profissionais de saúde sobre o cuidado à criança no contexto hospitalar são capazes de orientar práticas que acabam por organizar as interações sociais cujas crianças tomam parte, delineando as oportunidades que o meio oferece à criança para desenvolver saberes e valores em relação ao cuidado em saúde.

Deste modo, este trabalho inspira-se nas reflexões de Jodelet (2007) sobre imbricações entre representações e intervenção no que se refere ao diálogo estabelecido entre o conhecimento do cotidiano, contextos culturais, sociais, que compõem as vivências mediadas pela interação e práticas discursivas. Apresenta como objetivo compreender e identificar redes de significações acerca do cuidado à criança no contexto hospitalar, a partir de entrevistas realizadas com profissionais que trabalham em uma Enfermaria Pediátrica, após a implantação do projeto de extensão universitária Binje: em busca de autorias infantis no contexto hospitalar que, desde 2010, realiza semanalmente junto às crianças sessões de interação mediada pela narrativa Binje (Freire, 2013) retratando a relação de um menino com o adoecimento e o processo de hospitalização.

O eixo norteador deste estudo refere-se à análise de possíveis impactos do referido projeto na dinâmica do compartilhamento dos significados sobre o cuidado à criança em uma enfermaria pediátrica e toma a narrativa tanto como modalidade discursiva por meio da qual as práticas relacionadas ao projeto se dão, quanto como meio de acesso as significações da equipe de saúde. 


\section{Projeto Binje: elementos para se pensar as imbricações entre intervenção e representação social}

O objeto de análise deste estudo pauta-se na indissociabilidade entre saber e atuação/intervenção e adota as representações sociais como forma de compreensão sobre as realidades e as vias de ação sobre elas. Deste modo, assume o enunciado de Jodelet (2007) no qual a autora afirma que "uma intervenção vincula-se ao desejo de mudar o estado do campo de atuação e transformação de práticas" (p. 52). Como pano de fundo vislumbra-se a mudança baseada nas modificações das representações sociais, sobretudo em contextos institucionais onde se dá a interação entre aspectos da vida pessoal com uma coletividade.

Ao pensar na relação entre representações sociais e intervenção levou-se em consideração que: 1. a prática social depende da interpretação que os sujeitos sociais, indivíduos ou grupos fazem da sua realidade; 2 . as representações sociais, compreendidas como filtro referencial de leitura do mundo, guia de ação e sistema de orientação de condutas e das comunicações, são formas de saber sobre a realidade na mesma medida que são formas de atuação sobre ela; 3 . a atuação assume o status de intervenção e compromete-se a: a) identificar as representações compartilhadas no espaço de vida ou de ação particular dos sujeitos envolvidos - modo de pensar dos atores sociais; b) destacar as representações sociais que obstruem ou facilitam as práticas desejadas, aquelas que sustentam a identidade e propiciam aos atores sociais um modo de viver e atuar autêntico $e$ em acordo com suas necessidades. (Jodelet, 2007, p. 56)

Neste sentido, ao pensar a íntima relação entre representações sociais e intervenção compreende-se que as primeiras são convocadas para:

[...] encontrar os meios de ajudar os atores sociais, os grupos ou as comunidades, a melhorar suas condições de vida ou de trabalho, atingir uma existência satisfatória, cumprir suas necessidades, realizar seus desejos, respeitar seus direitos, fortalecer seus poderes ou simplesmente se conformar a objetivos considerados ótimos para o bem estar individual ou coletivo. (Jodelet, 2007, p. 57)

De acordou com a autora, por meio dos projetos de intervenção é possível criar condições favoráveis para a produção de novas representações dos objetos com os quais os sujeitos enfrentam, da realidade de seu mundo de vida, do seu envolvimento nela.

O projeto de intervenção Binje: em busca de autorias infantis no contexto hospitalar levou em consideração a proposição de Jodelet (2007) sobre as esferas de pertencimento das representações sociais (trans-subjetiva, intersubjetiva e subjetiva) e os estudos sobre narrativa tomando-a como um instrumento psicológico por meio do qual as representações são compartilhadas.

Deste modo, considera-se o estudo em diferentes níveis. No nível trans-subjetivo baseou-se na história do hospital e da pediatria enquanto uma especialidade médica e mais especificamente na história do hospital no qual o projeto se desenvolve cujo patrono respondia pelo apelido de Binje quando criança. Em um segundo momento, em consideração a esfera intersubjetiva, foi relevante a pesquisa de Carrijo (2013) intitulada: " $O$ hospital daqui e o hospital de lá": fronteiras simbólicas do lugar, segundo significações de crianças hospitalizadas para identificar vivências infantis emblemáticas em contexto de hospitalização. Este material, em diálogo com notas de campo do projeto de extensão Rede de Apoio à Educação Infantil: interfaces com a Psicologia e Pedagogia, orientou a elaboração 
do enredo da narrativa Binje que privilegiou os seguintes eixos temáticos: 1 . O hospital segundo a perspectiva da medicina flexneriana e da humanização; 2. O protagonismo da criança hospitalizada; 3. Estratégias de enfrentamento psicológico das vivências significadas como ameaçadoras; 4. Nomeação de sentimentos; 5 . O cuidado e o auto cuidado.

A narrativa é apresentada de duas formas: a primeira, na forma do livro Binje (Freire, 2013) regularmente distribuído na enfermaria pediátrica e a segunda na forma de contação de história por meio da atuação da personagem Dra. Ana Tsuru, especialista em crionçalogista, inspirada na metáfora da lenda dos Mil Tsurus, na imagem de criança onça e na noção de adulto atípico (Corsaro, 2005) - aquele que, na relação com a criança, não investe autoridade desnecessariamente.

As sessões semanais de contação de história, geralmente realizadas em grupo de crianças e acompanhadas pelos responsáveis, além de apresentarem a narrativa Binje possibilitam às crianças processos de elaboração de suas vivências no hospital, aspecto que permite a emergência das lógicas infantis no diálogo geracional entre as crianças e Dra. Ana Tsuru. Observa-se que além do vínculo que se estabelece, surge uma autorização concedida pela criança para a personagem interagir com conteúdos ameaçadores em uma dinâmica marcada pela compreensão empática e pelo respeito ao tempo de elaboração da criança.

As elaborações infantis revelam, na esfera subjetiva, importantes processos de significação seja em relação aos conteúdos relacionados ao adoecimento, a hospitalização, ao tratamento, seja vinculados a história de vida da criança, a conflitos familiares, dificuldades no processo de escolarização, conteúdos associados ao pertencimento comunitário e processos autorais de criação de narrativas próprias. Nota-se que nesta dimensão do trabalho algumas crianças são encaminhadas para o processo psicoterápico de modo a explorar zonas mais profundas do processo de significação.

\section{Sobre os dois eixos fundamentais na constituição do projeto Binje}

\section{Narrativas, representações sociais e contextos de interação}

A narrativa envolvida nos processos de atribuição de significações sobre a realidade pode ajudar a esclarecer movimentos de elaboração associados às representações sociais. Segundo Jovchelovitch (2002), narrativas são uma das principais formas de discurso por meio das quais as representações sociais são atualizadas e ganham vida, encontrando nelas algo parecido com um terreno privilegiado para se incubar e desenvolver. Isso porque as significações, e consequentemente as representações sociais, não são transmitidas soltas, mas imbricadas nelas.

Apesar de Moscovici (2003, 2012) não abordar diretamente o caráter narrativo do pensamento natural, ele marca que esse processo cognitivo tem como base a coerência de ordem social, e que por isso, sua elaboração ocorre durante as comunicações, afirmando que "pensamos com nossas bocas", para destacar a importância da conversação na gênese e partilha das representações. Assim, embora Jerome Bruner não seja um teórico com produções no âmbito da Teoria das representações sociais, seus trabalhos têm ajudado a esclarecer possíveis imbricações entre narrativas e o pensamento do senso comum. (Jovchelovitch, 2002; László, 2002; Volpato, 2002) 
Bruner $(2002,2014)$ entende que a cultura contém imagens, narrativas e um conjunto de ferramentas que possibilitam o acesso a um mapa de grande escala sobre como as transações ocorrem. Ele destaca que as narrativas apresentam uma gama de personagens canônicos, os ambientes nos quais eles operam, as ações que são admissíveis e compreensíveis. Sendo que por meio disso, fornecem orientações sobre papéis, identidades e de mundos possíveis dentro dos quais a ação, o pensamento e própria definição de si são permitidos ou desejáveis.

Com isso, o autor propõe que as pessoas armazenam tais modelos de mundo, tornando-as capazes de guiar sua percepção, pensamento e fala em determinados contextos. Eles funcionariam como mapas de compreensão da realidade que ajudariam o sujeito a se orientar de acordo com o que é esperado em sua cultura. Neste caso, é possível considerar que as representações sociais, como forma de conhecimentos compartilhados em uma cultura, sejam compreendidas como constructos que integram tais mapas de compreensão da realidade, se apresentando como matérias primas de sua estruturação.

Bruner (2001) ajuda a esclarecer que o processo de elaboração de narrativas que buscam organizar e significar vivências frente ao novo ou inesperado, relaciona os acontecimentos dentro de um esquema temporal de inícios, meios e fins, visando enquadrar o estranho dentro de gêneros ou roteiros culturalmente compartilhados, de modo a envolver estados intencionais e motivacionais dos personagens que atuam na história. Além disso, o autor destaca que esse tipo de elaboração, por mais convincente, sempre é passível de questionamento, conferindo a narrativa certa prontidão para a negociação, o que consequentemente pode implicar em processos de novas significações e novas construções narrativas.

Moscovici (2012) descreveu que o pensamento do senso comum implica, como todo pensamento, em um sistema de relações operatórias e um metassistema de relações de controle, de validação e de manutenção de coerência. Esse sistema de controle que organiza o material produzido pelo primeiro é composto por relações normativas que irão verificar e orientar a dimensão operatória (Moscovici, 2012). Por sua vez, Doise (2011) esclarece que o metassistema ou princípios organizadores da representação gerenciam discursos e tomadas de posição. São compostos por normas e princípios fortemente imbricados aos contextos sociais. Isso porque a dimensão operatória do pensamento é evocada em situações particulares nas quais pessoas assumem papéis sociais e identidades diferentes na relação com outras pessoas.

Com base nisso, compreende-se que determinadas configurações sociais podem indicar para um sujeito metassistemas que orientam a organização de representações na elaboração de narrativas. O que se observa é que contextos sociais fazem referências a metassistemas que vão orientar a organização narrativa das representações sociais de modo a buscar preservar identidades específicas.

Doise (2011) compreende que essa relação entre um conteúdo cognitivo e um metassistema relacional se faria presente desde a elaboração deste conteúdo. E mesmo separados, esse saber manteria uma assinatura, uma marca do processo relacional original. O autor explica que as relações de origem nas quais um julgamento é formado permanecem associadas a esse julgamento, e o investem com um valor correspondente a essas relações. Como consequência, surgem associados a esses saberes, uma marcação social. Assim, para ele, a noção de marcação social assinala a existência de uma pré-estruturação do contexto que organiza as interações e que conduz o indivíduo a regular suas atividades mentais em 
relação ao ambiente, mesmo quando se refere unicamente a um material simbólico, pois ao invocar paradigmas essa pré-estruturação funciona como pistas e suportes que ajudam o sujeito a se orientar.

Assim, ao narrar uma pessoa buscará organizar seu discurso de modo a considerar os marcadores sociais que se fazem presentes na interação entre atores sociais, seus saberes adquiridos anteriormente no contato com a cultura e suas motivações de modo a preservar sua identidade atualizada. Enfatiza-se assim, que narrativas são necessariamente intencionais e ao utilizarem determinados saberes em detrimento de outros, envolve processos de defesa identitária, além de realizarem um convite para compreender o mundo a partir de determinada perspectiva.

Deste modo, considera-se que na dinâmica das representações sociais existe uma relação estreita entre: construção de representações, memória coletiva, valores e regras transmitidas pelos grupos de pertença e a subjetividade de quem acessa esses constructos. Isso porque conhecimentos ou informações disponíveis são sempre trabalhados pelo sistema operatório de um sujeito, ainda que ele o faça com base em valores e normas presentes em contextos particulares. E com isso, observa-se que se na dimensão social está disponível às pessoas o acesso a diferentes tipos de saberes, elaborados em diversos contextos e com objetivos diferenciados, na dimensão subjetiva existe um sujeito social, localmente situado em contextos particulares de vida e de trabalho, que se apropria dessas representações presentes no espaço comum e fazem uso de diferentes formas de saber dependendo das circunstâncias particulares em que se encontram e dos interesses que possuem em determinado tempo e lugar.

Nesse sentido, tomar a representação social como um fenômeno associado à construção narrativa possibilita compreender a relação existente entre o mundo de vida nos quais as pessoas habitam e o processo de elaboração dos estados variáveis desse mundo que se torna inteligível e manejável. Com isso, o trabalho aqui apresentado parte do pressuposto de que a dimensão social tende a disponibilizar diferentes conhecimentos acerca do cuidado à criança no hospital, porém a dinâmica estabelecida nas interações vai mobilizar identidades, motivações e afetos que colocam em ação movimentos narrativos de significação dos profissionais de saúde, visando atribuir inteligibilidade aos contextos e justificar suas práticas.

\section{Considerações sobre a medicina científica ou flexneriana e o projeto de humanização da saúde}

Sobre as representações compartilhadas em contextos de cuidado hospitalares é possível delinear a existência de distintas representações que permeiam o atendimento a saúde das crianças aqui anunciadas como duas grandes narrativas presentes na memória social com potencial de influenciar a construção da realidade social: a medicina científica ou flexneriana e a perspectiva da humanização.

O modelo de saúde predominante na formação médica brasileira, inscrito na memória social há mais de 100 anos, é a Medicina científica, ou flexneriana, que compreende o corpo humano como uma máquina, sendo a doença representada como uma avaria e o tratamento como o conserto desse aparelho. Esse modelo aborda de forma reducionista os aspectos sociais e subjetivos da saúde, tendo como base a assistência à doença em seus 
aspectos individuais e biológicos, centrados no hospital, nas especialidades médicas e no uso intensivo de tecnologias. Essa visão mecanicista, biologista e reducionista também continua orientando a organização dos serviços de saúde, principalmente no âmbito hospitalar (Carlini, 2010).

Mais recentemente, na realidade brasileira, destaca-se a Política Nacional de Humanização (PNH) que investe, por meio do projeto Humaniza SUS, na valorização da autonomia e protagonismo de todos os sujeitos envolvidos no processo de saúde. Entendendo que humanizar não é apenas ofertar atendimento de qualidade articulado aos avanços tecnológicos, mas também propiciar acolhimento, o projeto estabelece a corresponsabilidade, protagonismo, vínculos solidários e participação coletiva como conceitos e pressupostos gerais de cuidado que se aplicam a todos os sujeitos independentes de faixa etária (Brasil, 2004).

Atualmente, na realidade brasileira, ocorre uma busca pela mudança na cultura de assistência à saúde, visando maior humanização dos serviços hospitalares. O objetivo é a criação de um novo modelo de atendimento pautado no respeito à vida humana, o que inclui maior atenção às singularidades da dimensão subjetiva do usuário.

Considerando mais especificamente o cuidado à criança no âmbito da saúde, Pereira (2006) observou que no surgimento da Pediatria, o papel do médico se delineou em oposição ao papel das mães consideradas como relapsas, despreparadas e desprovidas de conhecimentos técnicos e científicos. Assim, nesse processo, a mortalidade infantil foi compreendida como resultante de práticas familiares que desconheciam preceitos higiênicos e morais, acrescida da ignorância com relação à relevância do médico no momento inicial da doença infantil. Deste modo, elaborou-se um discurso sobre as mazelas infantis que se fundamenta no pressuposto de culpabilização da família, em especial à mãe.

A autora conta também que historicamente em um tempo que a Medicina científica começava a se segmentar em especialidades, a Pediatria fundamentou-se de forma distinta, visando um atendimento que abrangia toda e qualquer necessidade dessa parcela da população. Essas significações atreladas ao surgimento da Pediatria fazem com que ela se desenhasse marcada por uma narrativa que ressalta a busca por salvar vidas de crianças, estas últimas caracterizadas por sua dificuldade em se comunicar e por sua potencialidade em tornar-se adulto, precisando, para tanto, lidar com a responsabilidade dos pais pelo tratamento (pessoas sem conhecimento específico na área de saúde), e utilizando-se de saberes técnico-profissionais que incluem processos disciplinatórios e educativos.

Deste modo, observa-se que na esfera da trans-subjetividade se fazem presentes diferentes narrativas históricas sobre o cuidado em saúde. Elas revelam uma diversidade de valores, personagens e roteiros, privilegiando, cada uma delas, perspectivas que retratam e armazenam modelos de cuidado na área de saúde. Uma delas se relaciona com o delineamento da Medicina como um saber do campo científico, reduzindo o objeto de ação médica à cura biológica. Nessa perspectiva, o papel do médico é descrito como detentor do saber e o paciente como portador de uma condição clínica. Os valores ressaltados envolvem tecnologia, especialização e controle. Ainda nessa perspectiva, o desenvolvimento da Pediatria indicou que o cuidado voltado para a criança, apresentava o papel do médico relacionado com a proteção da infância, sendo a criança caracterizada tanto por sua dificuldade na comunicação quanto por seu devir. Com isso, a atuação médica ganhou também contornos educativos e disciplinares. 
A outra rede de significação sobre o cuidado em saúde, mais recente na memória social, apresenta-se associada aos movimentos de humanização que surgem justamente em resposta a uma visão reducionista do processo saúde-doença. Assim, aqui existe o destaque da dimensão ética e relacional, enfatizando valores como protagonismo, corresponsabilidade e autonomia dos diferentes personagens na produção de saúde. 0 objeto do cuidado é apresentado como incluindo aspectos sociais, psicológicos e comportamentais. Os médicos são apresentados como parte de uma equipe de profissionais que atuam juntamente com quem demanda atenção, estabelecendo vínculos e compartilhando decisões e responsabilidades.

Ao considerar que a inserção narrativa Binje no cenário investigado, juntamente com o delineamento de uma rotina para o cuidado de contar história na Pediatria, poderia causar ressonâncias nas narrativas dos profissionais sobre o cuidado às crianças no contexto hospitalar, este estudo reconhece o peso histórico-social das diferentes narrativas sobre o cuidado em saúde, entendendo que a equipe de profissionais pode utilizar tais constructos para compreender seu contexto de atuação, orientando suas próprias narrativas e veiculando esses saberes também em relação à criança atendida. Assim, esse estudo parte da ideia que as narrativas, sejam elas delineadas historicamente, adotadas culturalmente ou elaboradas a partir da conversação nas interações cotidianas, se apresentam como constructos capazes de organizar redes de significações, aglutinando representações sociais.

\section{Metodologia}

Os procedimentos adotados caracterizam um estudo de campo de orientação etnográfica constituído de observação participante e entrevistas semiestruturadas realizadas individualmente com 11 profissionais da Enfermaria Pediátrica. O critério de convite para a participação foi a possibilidade de contato que os profissionais tiveram com o projeto Binje. Foram convidadas a participar da pesquisa todas as profissionais que frequentavam as reuniões semanais da Equipe Multiprofissional de Atenção a Criança (EMAC), um grupo que tem por objetivo desenvolver práticas de atenção humanizadas na Pediatria e que participou do processo de implementação das atividades relacionadas à narrativa Binje (Freire, 2013). Além desses profissionais, a entrevista também foi proposta a duas pedagogas e duas técnicas de enfermagem que costumavam presenciar as sessões do projeto na brinquedoteca.

No total foram entrevistadas: 1 médica, 1 enfermeira, 2 técnicas em enfermagem, 2 psicólogas, 3 pedagogas, 1 assistente social e 1 nutricionista. De modo geral, é possível caracterizar esse grupo como formado por mulheres, predominantemente entre 30 a 59 anos, com Pós-Graduação e que trabalham na instituição há seis anos ou mais.

Os temas do roteiro de entrevista abordaram as crianças hospitalizadas, seus cuidadores, o trabalho realizado pela equipe e o projeto de extensão visando compreender e identificar redes de significações acerca do cuidado à criança no contexto hospitalar, a partir da inserção do projeto de extensão Binje: em busca de autorias infantis no contexto hospitalar neste cenário de investigação.

O material produzido pela transcrição das entrevistas foi processado no programa computacional IRAMUTEQ (Interface de R pour les Analyses Multidimensionnelles de Textes et de Questionnaires) que permitiu a realização da análise de Classificação Hierárquica 
Descendente (CHD).O programa IRAMUTEQ considerou $78,12 \%$ do material processado, correspondendo a um total de 771 segmentos de texto (ST) e organizando o discurso em quatro classes: Classe 1 - 257 ST (33,33\% do corpus analisado); Classe 2 - 104 ST (13,49\%); Classe 3 - 149 ST (19,33\%); e Classe 4 - 261 ST (33,85\%).

Para efeito deste trabalho será analisada apenas a classe 1 intitulada $A$ prática de sentar e contar história. A referida classe encontra-se inserida no eixo temático dedicado a ideia da Ludicidade como forma de cuidado humanizado.

\section{Análise e discussão da classe A prática de sentar e contar histórias}

Os nomes atribuídos às Classes e arranjos foram designados considerando o conteúdo discursivo selecionado pelo IRAMUTEQ, assim como as palavras mais características de cada Classe. A representação das relações de oposição e complementaridade entre essas Classes foi apresentada pelo programa através de um dendrograma:

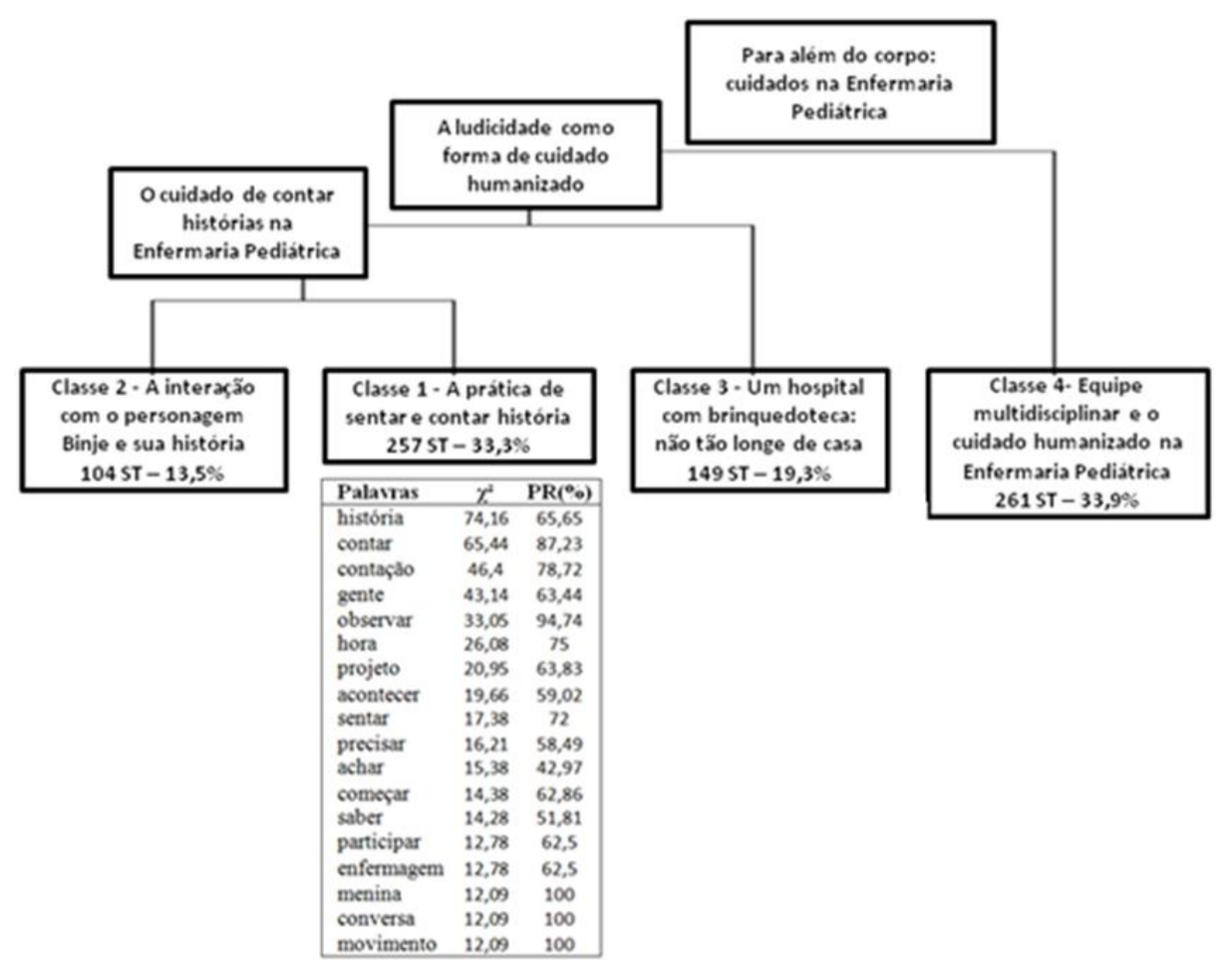

Figura 1 - Dendrograma de relação entre as Classes e perfil da Classe 1.

Através do dendrograma é possível perceber que o discurso se dividiu inicialmente em dois grandes eixos, um que apresenta mais especificamente os cuidados desenvolvidos pela Equipe Multidisciplinar e que se aproximam da Política de Humanização, e no outro se encontram narrativas que discutem o cuidado que envolve a ludicidade na Enfermaria Pediátrica. Essa demarcação indica a presença de um distanciamento entre discursos que abordam os cuidados envolvendo a ludicidade e os demais tipos de cuidados, ainda que ambos se relacionem à dimensão simbólica do cuidar e tenham como base a busca pela Humanização da atenção. 
O eixo que assinala a ludicidade como forma de cuidado também se subdivide, trazendo um bloco que discute mais especificamente a prática de contar história na Enfermaria Pediátrica e que abrange as Classes 1 (A prática de sentar e contar história) e Classe 2 (A interação com o personagem Binje e sua história); e outro, a Classe 3 (Um hospital com brinquedoteca: não tão longe de casa) que destaca mais especificamente as atividades lúdicas desenvolvidas pelos profissionais no cotidiano da Enfermaria e que se localizam principalmente no cenário da brinquedoteca.

O conteúdo da classe 1 apresentou-se associado às ações de cuidado desenvolvidas pelo projeto de extensão Binje: em busca de autorias infantis no contexto hospitalar e que envolvem sessões de contação de história. Assim, ela foi nomeada $A$ prática de sentar $e$ contar histórias, por aglutinar relatos sobre essa prática de cuidado na Enfermaria Pediátrica.

As palavras história, contar, contação, hora, projeto e acontecer indicam o conteúdo dessa classe associado às ações de cuidado desenvolvidas pelo projeto extensão. Mais especificamente os vocábulos achar e saber marcam a expressão das impressões sobre essas atividades, de forma que as narrativas indicaram diferentes níveis de aproximação com as atividades do projeto, destacando que no cenário da Pediatria existe, por parte de alguns profissionais, o desconhecimento desse tipo de ação, ou ainda, certa invisibilidade relacionada a essa prática de cuidado:

[...] então eu acho que precisa mais eu acho que existe um desconhecimento. Eu não sei se é um desconhecimento ou se não valorizam talvez por desconhecerem como funciona a contação da história, desvalorizam a própria situação em si [...] (Profissional 8, psicóloga)

[...] eu acho que quando houver a compreensão da equipe o projeto vai ganhar mais visibilidade aqui dentro. Não vai ser só o passarinho da brinquedoteca, não vai ser só mais o menininho da brinquedoteca e não vai ser só mais as meninas da Psicologia que vêm contar história. (Profissional 2, enfermeira)

Falas como essas, indicam a caracterização da prática de contar história como uma ação desenvolvida pela Psicologia, e que, portanto, precisa ser apresentada e justificada aos demais profissionais para que ocorra a adesão. Além disso, retrata a presença de um distanciamento simbólico entre ações que ocorrem nas sessões de contação e ações de cuidado que ocorrem na rotina dos demais profissionais.

É necessário destacar que a lógica da rotina hospitalar é hegemonicamente organizada com base nos princípios da Medicina científica ou flexneriana, que priorizam as demandas biológicas e valorizam as práticas médicas. Nesse sentido, as narrativas pareceram dialogar com a possibilidade de inserção da prática de contar história em um contexto de interação no qual a rotina hospitalar é demarcada pelo Procedimento Operacional Padrão (POP), documento que busca organizar uma pré-estruturação das ações de cuidado a serem desenvolvidas por cada categoria profissional no dia a dia da Enfermaria, estruturando boa parte do tempo de atuação da equipe, mas se apresentando pouco flexível para integrar a dimensão da novidade, tal como a prática de contar história promovida pelo projeto de extensão:

Eu acho que falta nós estabelecermos a rotina para isso. [...] Porque o que acaba complicando para a Enfermagem é a questão do horário, mas se eu tenho um horário $X$ e $Y$ e eu sei que é aquela pessoa que vai estar presente, então a gente pode se organizar para que naquele horário ela já tenha concluído as atividades e que os colegas que vão ficar lá possam continuar o que for necessário. [...] (Profissional 2, enfermeira) 
Eu acho que sinceramente nós participamos muito pouco das histórias quando as crianças estão reunidas. Bem que a contadora de história todas às vezes nos chama para participar, mas nunca dá para nós irmos. Porque é dia de semana, é aquela correria, é uma coisa ou outra que nós temos que fazer. Talvez se nós participássemos mais, ficaria melhor, e assim eles nos contariam. (Profissional 10, técnica de enfermagem)

[...] Na última semana, eu estava aqui de longe vendo vocês contarem e, assim, observei a forma como a criança reagiu, como a criança ouviu o projeto. $E$ dois dias depois ela pediu que a gente contasse história, pediu para contar a história dos três porquinhos. Foi tão engraçado porque os profissionais não têm o contato com o contar história, e ela pediu para a nutricionista. [...]E no outro dia, quando eu cheguei, ela: 'Vamos lá que eu quero história de novo!' Pois, é história e juntou tudo. Ela achou bem engraçado e disse: 'Que interessante!'. Mas tudo isso foi por conta da contação de história de vocês. A solicitação dela para a contação de história veio motivada pela contação de história de vocês. Eu faço esse link. Só que os outros profissionais também precisariam dar valorização para esse momento, entendeu? [...] (Profissional 8, psicóloga)

Observou-se nos discursos que a inclusão dos demais profissionais como parte das ações do projeto está relacionada com a possibilidade de compreenderem como funciona esse tipo de cuidado, assim como de perceberem possíveis resultados que ele pode apresentar em relação a melhoria do processo de hospitalização da criança, ou mesmo da sua própria prática profissional. Com relação a isso, destaca-se o movimento de alguns entrevistados por se colocar no exercício da reflexão durante a entrevista, elaborando em suas narrativas as possíveis funções desse tipo de atividade, apresentando algumas significações e justificativas sobre essa prática de cuidado ao associá-las com os objetivos essenciais de recuperação da saúde em sua dimensão biológica.

Com isso, compreende-se que se não for possível para o profissional esclarecer as funções de determinadas ações, estas podem ser desvalorizadas em relação suas próprias práticas de cuidado, tornando-se mais difícil que esse profissional consiga reorganizar sua rotina para integrar sua participação no projeto, principalmente se ela se encontra relacionada diretamente com os cuidados da dimensão corporal e biológica, como no caso da Enfermagem.

Mas, para além dos objetivos institucionais marcados diretamente por essa dimensão orgânica, a valorização da prática de contar história apareceu ancorada junto às ideias de humanização do cuidado na Enfermaria:

[...] a equipe olhando vocês fazerem aquilo, dando aquela importância. Eu acho que ela foi influenciada por isso, pela atitude em relação à criança. De você ter aquela delicadeza de contar uma história para uma criança nessa situação, em que elas possam falar [...] (Profissional 7, médica)

Assim, apesar de não ser reconhecido como uma forma fundamental de cuidado no hospital (por não estar diretamente ligado às necessidades biológicas), o contar história tem seu valor reconhecido quando ancorado ao movimento de humanização, que se preocupa com o acolhimento das pessoas atendidas e melhoria na qualidade da vivência de hospitalização. Com base nisso, as narrativas indicaram que a prática de contar história no hospital tem ampliado o espaço no qual se desenvolvem relações menos assimétricas, favorecendo as possibilidades de interações e diálogos entre crianças e adultos.

A Classe 1 foi nomeada A prática de sentar e contar história como forma de indicar a aglutinação das narrativas dos profissionais sobre o contar histórias como uma forma de cuidado no hospital. Elas indicaram a primazia dos cuidados na dimensão biológica e corporal na rotina hospitalar que pode dificultar a adesão ao contar história como uma prática integrada a ações dos profissionais, mas ao mesmo tempo, retrataram a ancoragem 
dessa prática como um cuidado próximo a ideia de humanização, reconhecendo sua importância no acolhimento e promoção de relações mais horizontalizadas nos processos de hospitalização orientadas pela ideia de estar com.

\section{Considerações finais}

O estudo ora desenvolvido tornou possível a análise das representações sociais sobre as práticas de cuidado em saúde deixando ver tanto um processo de aproximação e identificação com as redes de significados propostas pelo projeto, quanto de afastamento e diferenciação em um movimento de reafirmar as práticas adotadas distintas das propostas pelo projeto.

Neste exercício de identificação e diferenciação foi possível destacar elementos em torno dos quais se estruturam narrativas dos profissionais sobre o cuidado em saúde de crianças. Destaca-se a noção de tempo instituído pela rotina hospitalar, da preponderância dos aspectos biológicos em detrimento aos demais e da abordagem disciplinar organizando o trabalho de assistência à saúde por meio de especialidades. Quando diante de uma proposição na qual ganha visibilidade o tempo do estar com e os aspectos vivenciais da hospitalização, as significações dos profissionais de saúde revelam a identificação com os elementos de humanização sem, no entanto, se anunciarem como partícipes do processo.

Segundo os profissionais de saúde consultados, as práticas de cuidado visíveis são aquelas previstas pelo Procedimento Operacional Padrão (POP), que anunciam a representação do cuidar por meio de scripts instituídos e práticas rotinizadas prioritariamente dedicadas à atenção ao corpo adoecido e suas necessidades. Deste modo, POP seria a objetivação da representação de um cuidado em saúde ancorado nas narrativas da Medicina científica ou flexneriana. Por sua vez, sentar e contar histórias são práticas que podem ser interpretadas como objetivação das práticas de cuidado desenvolvidas pelo projeto Binje, estas foram significadas como práticas distantes da Enfermagem e exclusivas da Psicologia.

Essa diferenciação com relação às práticas de cuidado é justificada seja pela falta de conhecimento sobre as implicações da narrativa no processo de significação e sua relação coma saúde integral da criança, seja pela perspectiva disciplinar de organização do trabalho em contexto hospitalar. De qualquer forma, não deve escapar no contexto desta análise o fato de práticas ancoradas na narrativa da humanização em saúde impactarem as representações indenitárias dos profissionais da Enfermaria promovendo ora movimentos de distanciamento, ora de aproximação.

No que se refere à atitude de adulto atípico assumida pelos representantes do projeto Binje, ressalta-se a visibilidade do compartilhamento desta significação e o seu potencial dialógico com a equipe de profissionais da saúde. Não obstante a análise da médica, chefe do setor, notas de observação anunciam a existência de crianças pedindo para os profissionais contarem histórias a elas demandando a ampliação das práticas de cuidado no interior da rotina organizada pelo POP, de certa forma, subvertendo o tempo cronológico em nome do tempo do estar com. Este dado abre novas perspectivas de análise anunciando a criança como fonte de influência social cujas narrativas são capazes de forjar mudanças no processo representacional de um coletivo de adultos. 
De forma geral, por meio das práticas de cuidado propostas pelo projeto de intervenção, foi possível reconhecera existência, no cenário da Enfermaria Pediátrica investigada, redes distintas de significações sobre o cuidado de crianças no contexto hospitalar que se fazem presentes junto aos profissionais entrevistados. Elas remetem historicamente tanto ao paradigma da Medicina flexneriana, quanto ao da Política Nacional de Humanização $(\mathrm{PNH})$, e se apresentaram como matéria prima para a elaboração de narrativas frente a entrevista, retratando diferentes contextos de interação nas quais as práticas de cuidado à criança podem acontecer no hospital.

\section{Referências}

Arendt, H. (1990). Entre o passado e o futuro. (Mauro W. Barbosa, Trad.). (5a. ed.). São Paulo: Perspectiva.

Bauer, M. W., \& Gaskell, G. (1999). Towards a paradigm for research on social representations. Journal for the Theory of social behavior, 29(2), 163-186.

Brasil. Ministério da Saúde. Secretaria-Executiva. Núcleo Técnico da Política Nacional de Humanização. (2004). Humaniza SUS: política nacional de humanização: documento base para gestores e trabalhadores do SUS. Ministério da Saúde, Secretaria-Executiva, Núcleo Técnico da Política Nacional de Humanização (2ª . ed.). Brasília: Ministério da Saúde.

Bruner, J. (2001). A cultura da Educação (Marcos A. G. Domingues, Trad.). Porto Alegre: Artmed.

Bruner, J. (2002). Realidade mental, mundos possíveis (Marcos A. G. Domingues, Trad.). Porto Alegre: Artmed.

Bruner, J. (2008). Actos de significado (Vanda Prazeres, Trad.). Lisboa: Edições 70.

Bruner, J. (2014). Fabricando histórias: direito, literatura, vida (Fernando L. Cássio, Trad.). São Paulo: Letra e Voz.

Camargo, B. V., \& Justo, A. M. (2014). Estudos qualitativos e o uso de software para análises lexicais. In: X Seminário Analítico Internacional de Temas Interdisciplinares e II Seminário Internacional de Pesquisa Inovadora na/para Formação de Professores. Duque de Caxias: Rio de Janeiro, pp. 37-54. Disponível em: <https://drive.google.com/drive/u/1/folders/0B1sJtjYHLc94QnAxQkM5RmM3MVU>.

Carlini, R. (2010). Implantação da disciplina de atenção básica à saúde no curso de Medicina na Universidade Federal do Paraná: aspectos psicossociais e educativos. Dissertação de Mestrado, Universidade Federal do Paraná, Curitiba, PR, Brasil.

Carrijo, M. L. R. (2013). "O hospital daqui e o hospital de lá": fronteiras simbólicas do lugar, segundo significações de crianças hospitalizadas. Dissertação de Mestrado, Universidade Federal de Mato Grosso, Cuiabá, MT, Brasil.

Corsaro, W. A. (2005). Entrada no campo, aceitação e natureza da participação nos estudos etnográficos com crianças pequenas. Revista Educação e Sociedade, 26(91), 443-464.

Doise, W. (2011). Sistema e metassistema. In A. M. O. Almeida, M. F. S. Santos \& Z. A. Trindade (Orgs.). Teoria das representações sociais: 50 anos (pp.123-156). Brasília: Technopolitik.

Freire, D. (2013). Binje. Cuiabá: EdUFMT.

Jodelet, D. (2001). As representações sociais um domínio em expansão. In D. Jodelet (Org.). As representações sociais. (Lílian Ulup, Trad., pp. 17-43). Rio de Janeiro: EdUERJ.

Jodelet, D. (2005). Experiência e representações sociais. In M. S. S. Menin \& A. M. Shimizu (Orgs.). Experiência e representação social: questões teóricas e metodológicas (pp. 23-56). São Paulo: Casa do Psicólogo.

Jodelet, D. (2007). Imbricações entre representações sociais e intervenção. In A. S. P Moreira \& B. V. Camargo (Orgs.). Contribuições para teoria e o método de estudos das representações sociais (pp. 45-74). João Pessoa: Editora Universitária da UFPB. 
Jovchelovitch, S. (2002). Social representations and narrative: stories of public life in Brazil. In J. László \& W. S. Rogers. Narrative approaches in Social Psychology (pp. 47-58). Budapeste: New Mandate.

Jovchelovitch, S. (2008). Os contextos do saber: representações, comunidade e cultura. (Pedrinho A. Guareschi, Trad.). Petrópolis, RJ: Vozes.

László, J. (2002). Narrative organization of social representations. In J. László \& W. S. Rogers. Narrative approaches in Social Psychology (pp. 28-46). Budapeste: New Mandate.

Moscovici, S. (2003). Representações sociais: investigações em psicologia social (Pedrinho A. Guareschi, Trad.). Petrópolis, RJ: Vozes.

Moscovici, S. (2012). A Psicanálise, sua imagem e seu público. (Sonia Fuhrmann, Trad.). Petrópolis, RJ: Vozes.

Vigotski, L. S. (2010). Quarta aula: a questão do meio na Pedologia. (Márcia Pileggi Vinha, Trad.). Psicologia USP, São Paulo, 21(4), 681-701.

Volpato, A. C. (2002). Social representations and literary texts. In J. László \& W. S. Rogers. Narrative approaches in Social Psychology (pp. 74-87). Budapeste: New Mandate. 